\title{
Gastric intestinal metaplasia as detected by a monoclonal antibody is highly associated with gastric adenocarcinoma
}

\author{
Z K Mirza, K K Das, J Slate, R N Mapitigama, P S Amenta, L H Griffel, L Ramsundar, \\ J Watari, K Yokota, H Tanabe, T Sato, Y Kohgo, K M Das
}

See end of article for authors' affiliations

Correspondence to: Dr K M Das Dr K M Das,
UMDNJ-Robert Wood Johnson Medical School, 1 Robert Wood Johnson Place, New Brunswick, NJ 08903, USA

Daskm@umdnj.edu

Accepted for publication 17 December 2002

\begin{abstract}
Background: Some forms of gastric intestinal metaplasia (GIM) may be precancerous but the cellular phenotype that predisposes to gastric carcinogenesis is not well characterised. Mucin staining, as a means of differentiating GIM, is difficult. A monoclonal antibody, mAb Das- 1 (initially called $7 \mathrm{E}_{12} \mathrm{H}_{12}$ ), whose staining is phenotypically specific to colon epithelium, was used to investigate this issue. Methods: Using mAb Das-1, by a sensitive immunoperoxidase assay, we examined histologically confirmed GIM specimens from two countries, the USA and Japan. A total of 150 patients comprised three groups: group A, GIM (fields away from the cancer area) from patients with gastric carcinoma $(n=60)$; group B, GIM with chronic gastritis (without gastric carcinoma) $(n=72)$; and group $C$, chronic gastritis without GIM ( $n=18)$.

Results: Fifty six of 60 (93\%) patients with GIM (both goblet and non-goblet metaplastic cells) from group $A$ reacted intensely with mAb Das-1. Cancer areas from the same 56 patients also reacted. In contrast, $25 / 72(35 \%)$ samples of GIM from patients in group B reacted with mAb Das-1 (group A v $B, p<0.0001)$. None of the samples from group $C$ reacted with the $m A b$.

Conclusions: Reactivity of $\mathrm{mAb}$ Das- 1 is clinically useful to simplify and differentiate the phenotypes of GIM. The colonic phenotype of GIM, as identified by mAb Das-1, is strongly associated with gastric carcinoma.
\end{abstract}

M orphological changes in the mucosa of the stomach, resembling that of the intestine, constitute the condition known as intestinal metaplasia. Gastric intestinal metaplasia (GIM) is not a single entity but rather a heterogeneous group of metaplastic changes. ${ }^{1}$ Matsukura et al divided GIM into complete (small intestinal) and incomplete (colonic) varieties using enzyme techniques. ${ }^{2}$ Another classification categorised GIM into three types: I (complete), and II and III (incomplete). ${ }^{3}$ This is based on the fact that small intestinal goblet cells produce sialoglycoprotein that stains with periodic acid-Schiff (PAS) and alcian blue $(\mathrm{AB})$, and colonic goblet cells produce sulphomucin that is detected by $\mathrm{AB} /$ high iron diamine (HID) staining. ${ }^{145}$

Incomplete GIM appears to carry the highest preneoplastic potential for the intestinal variety of gastric carcinoma, which is the most common type of gastric carcinoma; even though some studies have also linked complete GIM with gastric carcinoma. ${ }^{6}$ Using histological and histochemical mucin staining techniques, it has been difficult to accurately define the phenotypic differentiation of GIM due to observer dependent variability in identifying subtle colour differences. This situation is often further complicated by the coexistence of different types of GIM and the presence of "mosaic cases", which have been reported to occur in $41 \%$ of patients. A biomarker(s) to reliably differentiate various types of GIM, and identify patients who may be at a higher risk of developing gastric carcinoma, would be clinically very useful.

Using a colon epithelial protein, we developed a novel murine monoclonal antibody, mAb Das-1 (formerly known as $7 \mathrm{E}_{12} \mathrm{H}_{12}$ IgM isotype), that reacts with colonic epithelium. Using both immunoperoxidase and immunofluorescence assays, we and others have independently demonstrated that mAb Das-1 specifically reacts with colonic epithelium (both goblet and non-goblet absorptive cells) but not with small intestinal enterocytes (including goblet cells) from the jejunum or ileum, or normal epithelium from the rest of the gastrointestinal tract. ${ }^{89}$ Although mAb Das-1 does not react with normal gastric and oesophageal epithelium, it reacts sensitively $(95 \%)$ and specifically (100\%) with Barrett's epithelium and adenocarcinoma of the oesophagus, indicating a strong association of its reactivity to this precancerous condition. ${ }^{10} 11$

In the present study, we explored if mAb Das-1 reactivity helps to identify the colonic phenotype of metaplasia in the stomach and its association with gastric carcinoma. We examined the immunoreactivity of the mAb against the tissue with different histological spectra of chronic gastritis beginning at an early stage before the development of GIM, in the intermediate stage when GIM had developed but no cancer was detectable, and finally in the stage where GIM was associated with gastric carcinoma. As gastric carcinoma is more common in Japan, we compared the reactivity in the tissue specimens obtained from the USA (New Jersey, NJ) and Japan.

\section{MATERIALS AND METHODS}

Paraffin embedded tissue blocks were obtained from 150 patients from NJ and Japan.

\section{Group A ( $n=60)$}

We used the computer database of the pathology departments to randomly select 60 tissue blocks with a diagnosis of GIM associated with gastric carcinoma. Thirty five patients from Japan (group $\mathrm{A}_{1}$ ) and 25 from NJ (group $\mathrm{A}_{2}$ ) were included.

Abbreviations: $A B$, alcian blue; $G I M$, gastric intestinal metaplasia; $H I D$ high iron diamine; PAS, periodic acid-Schiff; $\mathrm{mAb}$, monoclonal antibody; $\mathrm{H} \& \mathrm{E}$, haematoxylin-eosin; NJ, New Jersey. 
Table 1 Patient demographics

\begin{tabular}{lll}
\hline Group* & Mean (SD) age (y) & Males (\%) \\
\hline Group A $(n=60)$ & $68.8(10.0)$ & 60 \\
Group B $(n=72)$ & $64.9(17.5)$ & 53 \\
Group C $(n=18)$ & $62.8(15)$ & 72 \\
\hline
\end{tabular}

*Group A included gastric intestinal metaplasia (GIM) tissue away from the cancer areas as well as cancer tissue (surgical specimens) in patients from both Japan $(n=35)$ and New Jersey $(n=25)$.

Group B represents GIM tissue (biopsy specimens) from patients without gastric carcinoma (from Japan $(n=31)$ and New Jersey $(n=41))$

Group $\mathrm{C}$ represents gastric mucosal biopsy specimens with chronic gastritis with or without ulcer, but no GIM.

Age and sex distributions were not statistically different between the three groups.

For each of these 60 patients, paired samples of stomach (surgical specimens) included both cancer areas and histologically proved GIM areas away from the cancer segments.

\section{Group B (n=72)}

Biopsy tissue specimens containing GIM without gastric carcinoma were obtained both from Japan (group $B_{1}, n=31$ ) and NJ (group $B_{2}, n=41$ ).

\section{Group C ( $\mathrm{n}=18)$}

Eighteen biopsy samples were obtained from Japan with chronic gastritis, without evidence of GIM. The biopsy samples in groups $\mathrm{B}$ and $\mathrm{C}$ were obtained during routine upper endoscopy procedures for a variety of indications (usually dyspepsia and peptic ulcer disease) other than gastric carcinoma.

Five serial $5 \mu \mathrm{m}$ sections were obtained from all of the blocks. Haematoxylin-eosin (HEE) staining was performed on the first and last section cut from each block and reviewed to ensure the presence of histological abnormalities in both of the sections from the same block. The second to fourth sections were used for immunohistochemical studies. All samples from groups A and B (excluding cancer blocks) had GIM that was observed in both the initial and final H\&E sections. One of the sections from each patient was examined with mAb Das-1 using a sensitive immunoperoxidase assay, as described previously. ${ }^{11}$ Each experiment also included at least two slides of normal colon and jejunal tissue sections as positive and negative controls, respectively. Reactivity to $\mathrm{mAb}$ Das- 1 was considered positive if a crisp golden brown staining of cells was present. Two investigators (ZKM and KMD) and a single pathologist (PSA) reviewed each slide together. A substantial number of cells, and more than one gland, had to be reactive to $\mathrm{mAb}$ Das-1 before a specimen was considered positive. If only an occasional goblet cell was stained, the sample was considered negative. There was agreement among the investigators more than $95 \%$ of the time.

Using standard protocols, ${ }^{12}$ 76/132 GIM tissue samples (group A, 35; group B, 41) were also stained with $\mathrm{AB}$ ( $\mathrm{pH} 2.5$ )/ PAS and AB ( $\mathrm{pH} 2.5) / \mathrm{HID}$ to further subcategorise GIM into various types or "mixed" varieties, based on different colours of mucins displayed by neutral versus sialo or sulphomucins. The remaining tissue samples were not available for mucin staining because of the small size of the tissue in which deeper sections did not have enough mucosa. "Mixed" variety was defined as the presence of both complete and incomplete GIM types in the same tissue section, without a clear predominance of either type. A sample was considered having "predominantly" complete or incomplete if either variety represented more than $75 \%$ of the GIM area. Coded slides of mucin staining were interpreted by the single pathologist (PSA). Subsequently, the code was broken and staining of mAb Das- 1 and mucin stains were compared to identify the corresponding areas.
A mAb Das-1 reactivity to GIM

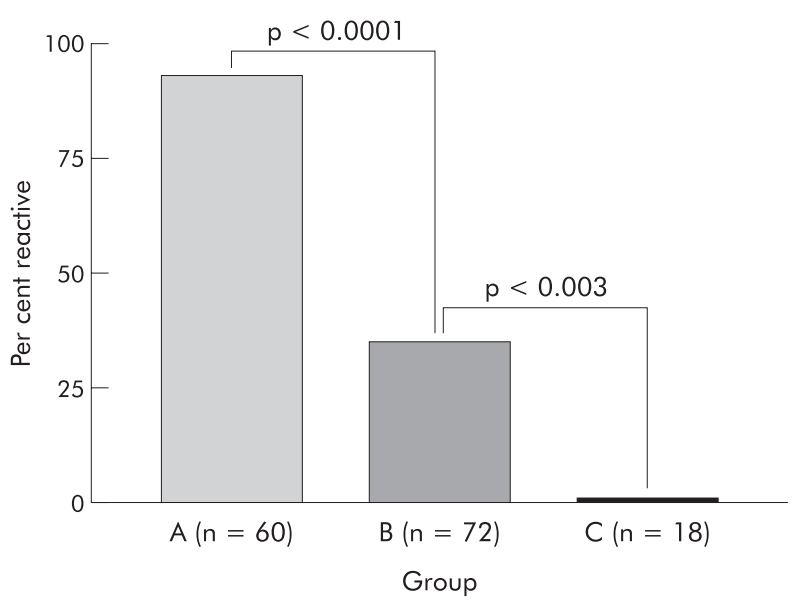

B GIM reactivity to $m A b$ Das- 1

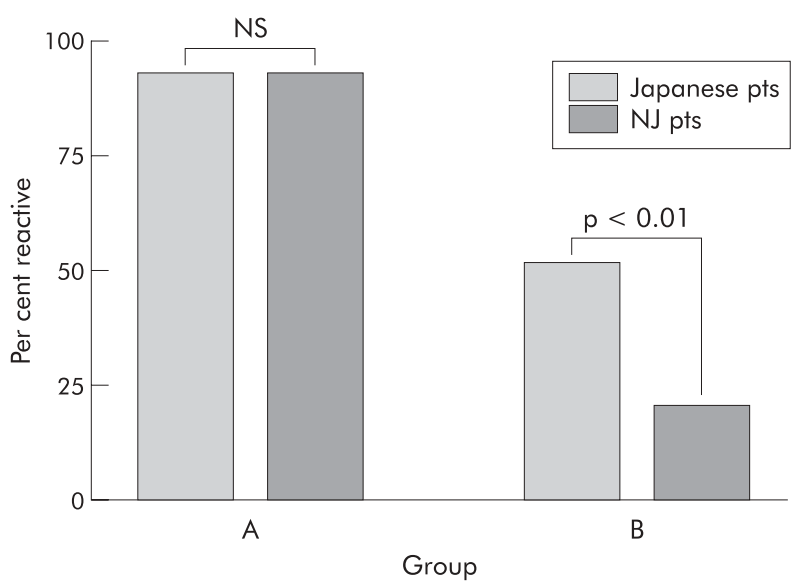

Figure 1 Group A represents gastric intestinal metaplasia (GIM) tissue from patients with gastric carcinoma located away from the cancer area, group B represents GIM tissue from patients without gastric carcinoma, and group $C$ represents gastric mucosal biopsies (with no GIM) obtained during routine upper endoscopy (used as controls). (A) Statistical analyses among the total patient groups from Japan and New Jersey (NJ). (B) Differences in each group and between the two countries. $A_{1}$ versus $B_{1}, p<0.0001 ; A_{2}$ versus $B_{2}$, $p<0.0001 ; A_{1}$ versus $A_{2}$, not significant; $B_{1}$ versus $B_{2}, p<0.01$.

\section{RESULTS}

Demographic data of patients in group A (GIM from patients with gastric carcinoma), group B (GIM without associated gastric carcinoma), and group C (chronic gastritis tissue without GIM) are shown in table 1 . There were no statistically significant differences among the three groups. Within group A, mean age (SD) for Japanese patients (group $A_{1}$ ) was 65.5 (9) years (range 43-82) and mean age of patients from NJ (group $\mathrm{A}_{2}$ ) was 78.4 (5.9) years (range 69-91) $(\mathrm{p}<0.002)$. However, in group $\mathrm{B}$, there were no significant differences in age; mean (SD) age of patients from Japan (group $B_{1}$ ) was 60 (14) years (range 18-76) and in patients from NJ (group $\mathrm{B}_{2}$ ), 63 (19) years (range 31-92).

Fifty six of 60 (93\%) samples of GIM from carcinoma patients, away from the cancer area (group A), reacted intensely with mAb Das-1. These included 33/35 (94\%) patients from Japan (group $A_{1}$ ) and 23/25 (92\%) patients from NJ (group $\mathrm{A}_{2}$ ) (fig 1). Both goblet and non-goblet metaplastic cells only in the GIM areas clearly reacted with mAb Das-1 ( fig 2 ). The rest of the gastric tissue was negative. In contrast with group A, only 25/72 (35\%) GIM samples from patients without gastric carcinoma (group B) reacted with mAb Das- 1 (fig 3C) while $65 \%$ did not react (fig 3F). None of the samples with 

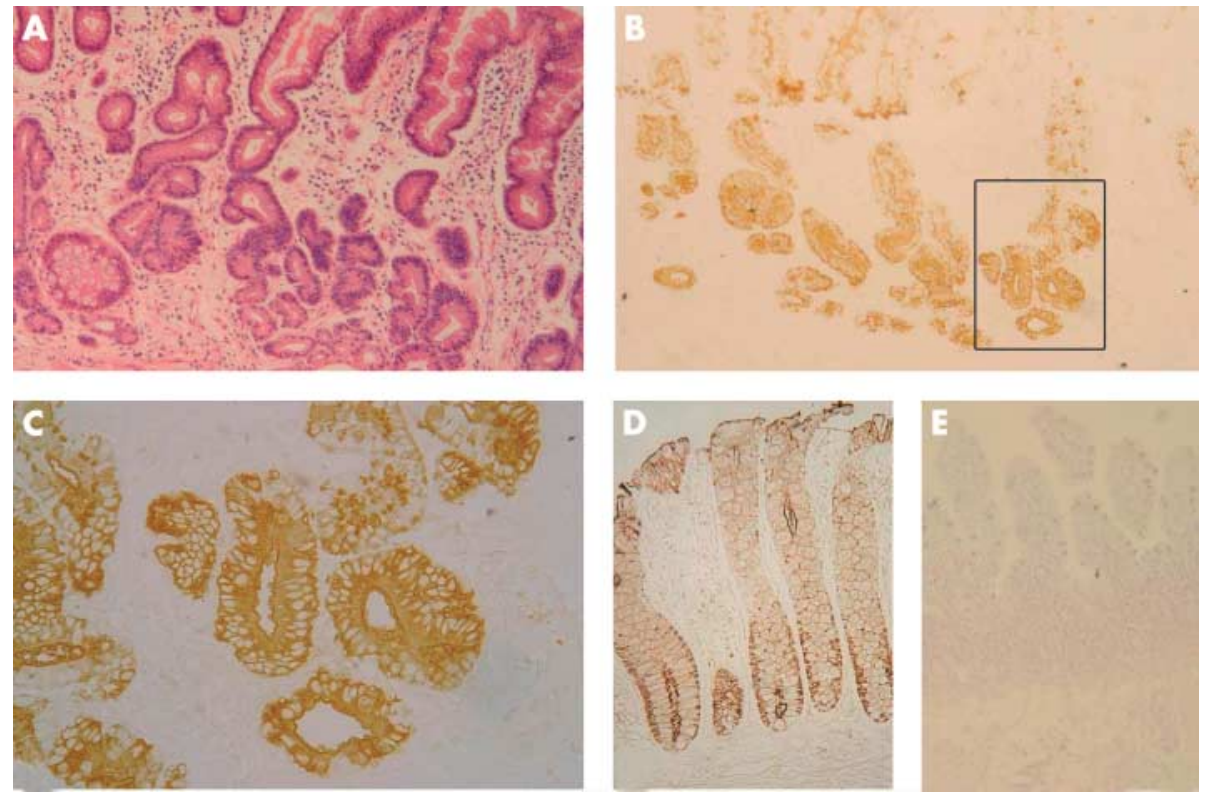

Figure 2 Various stainings of the serial sections from the antrum of the stomach with gastric intestinal metaplasia (GIM) (away from the gastric carcinoma area) from group A (original magnification 160x for each part except (E) (250x)). (A) Haematoxylin-eosin staining showing preponderance of goblet cells indicating the presence of GIM. (B) Immunoperoxidase staining with the monoclonal antibody mAb Das-1 showing specific reactivity of the metaplastic glands. Reactivity is clearly evident both in goblet and non- goblet cells. Note there is no reactivity with the rest of the stomach mucosa. (C) Higher magnification of the boxed area from (B). Intense reactivity of mAb Das-1 against the glandular epithelium, including both non-goblet and goblet cells is evident. Reactivity is intense along the basolateral and apical domains.

(D) Immunoperoxidase staining of normal colon mucosa with mAb Das-1 as a positive control. The reactivity (golden brown colour) is seen in both goblet and non-goblet cells with no reactivity of the lamina propria. Reactivity is more intense in the crypt area along the basolateral domain. (E) Immunoperoxidase staining of the jejunal mucosa with mAb Das-1 and counterstained with toluidine blue. mAb Das-1 did not react with the jejunal enterocytes.

chronic gastritis without GIM (group C) reacted with the antibody. The difference between the immunoreactivity of mAb Das- 1 against GIM in group A versus group B and group $B$ versus $C$ was highly statistically significant $(\mathrm{p}<0.0001$ and $\mathrm{p}<0.003$, respectively) (fig 1A). The cancer area from each of the 56/60 patients from group A, whose GIM tissue samples (away from the cancer area) were positive with mAb Das-1, also reacted with the $\mathrm{mAb}$ (fig 4).

Although the reactivity of mAb Das-1 against GIM associated with cancer was similar in patients from Japan $\left(\mathrm{A}_{1}\right)$
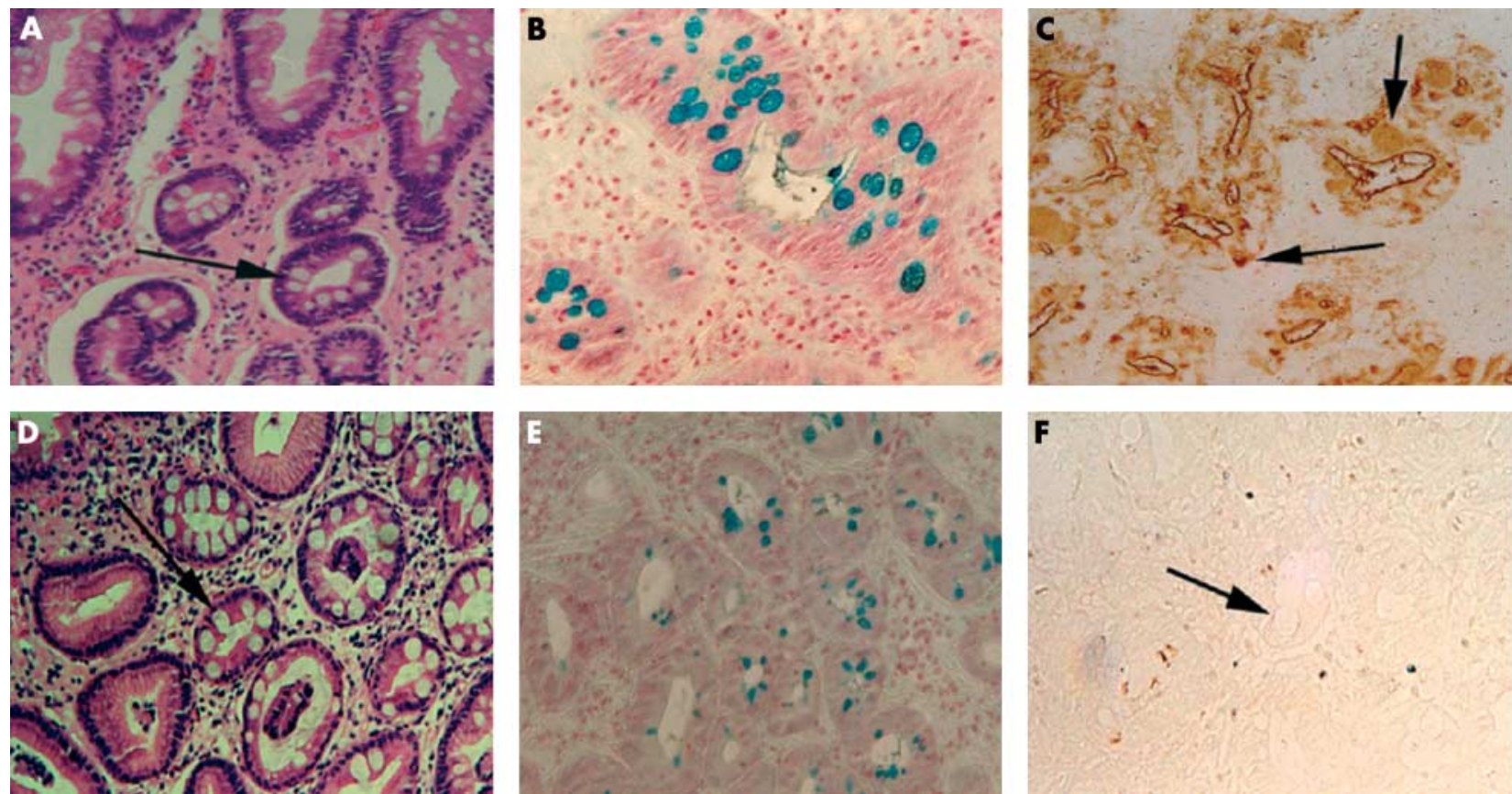

Figure 3 Serial sections of formalin fixed paraffin embedded biopsy tissue from two patients with gastric intestinal metaplasia (GIM) without carcinoma (group B). Haematoxylin-eosin staining (A, D), alcian blue/high iron diamine staining (B, E), and immunoperoxidase assay with the monoclonal antibody mAb Das- $(C, F)$. (A-C) is trom the same patient and (D-F) from the second patient. mAb Das-1 stained both goblet cells (shorter arrow) and metaplastic non-goblet cells (longer arrow) in the glands (C). While GIM is clearly evident with the presence of goblet cells $(D, E), m A b$ Das-1 did not stain the glands (F). The arrow shows the unstained goblet cells (original magnification 160x for each part). 

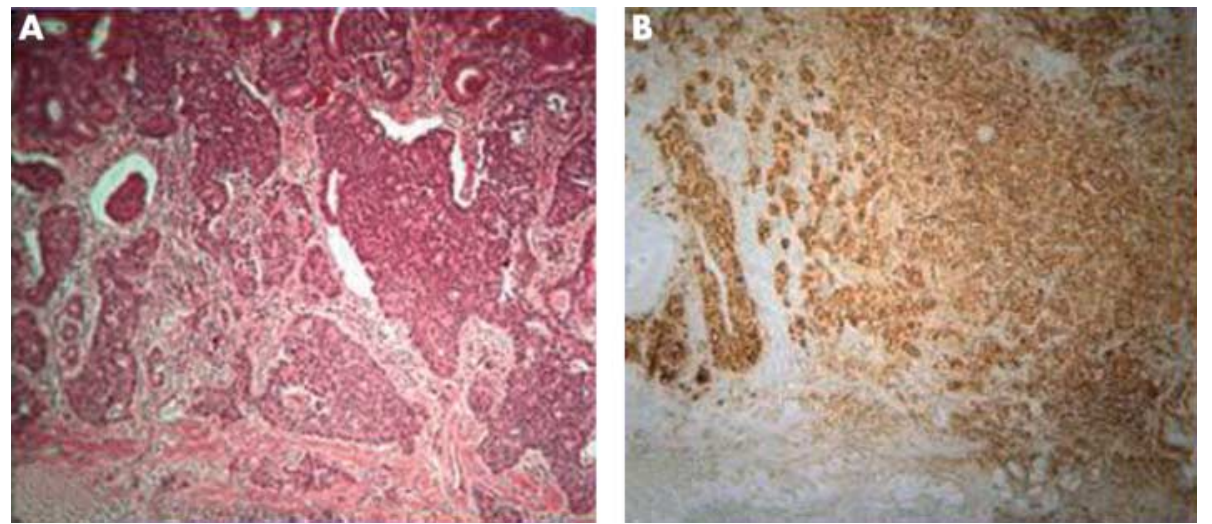

Figure 4 Haematoxylin-eosin (A) and immunoperoxidase (B) staining of the serial sections from a gastric carcinoma specimen. Intense cytoplasmic staining of the cancer cells with monoclonal antibody mAb Das-1 is clearly evident (original magnification 160x).

and NJ $\left(\mathrm{A}_{2}\right)$, in patients with GIM without cancer (group B) the reactivity in Japanese patients ( $\operatorname{subgroup} \mathrm{B}_{1}$ ) was higher $(52 \%)$ compared with NJ patients $(22 \%)$ ( subgroup $\mathrm{B}_{2}$ ). This difference was statistically significant $(\mathrm{p}<0.01)$ (fig lB). The difference between patients in subgroups $\mathrm{B}_{1}$ and $\mathrm{B}_{2}$ may be due to a higher prevalence of Helicobacter pylori infection in Japanese patients. $H$ pylori status was available for each of 31 Japanese patients (group $B_{1}$ ) but not for the NJ group $\left(B_{2}\right)$. Nineteen of $31(61 \%)$ patients were $H$ pylori positive whereas 12 were negative. Indeed, among these Japanese patients, mAb Das-1 reactivity was higher $(13 / 19 ; 68 \%)$ in the GIM associated with the $H$ pylori positive group compared with the $H$ pylori negative group $(3 / 12 ; 25 \%)$. This difference was highly statistically significant $(\mathrm{p}<0.001)$.

Each of the samples of GIM that reacted positively with mAb Das-1 showed intense, mostly cytoplasmic, staining in the goblet cells. In non-goblet metaplastic cells, reactivity was more intense in the basolateral and apical areas (fig 2B, 2C), with light cytoplasmic staining. In the cancer tissue, staining with mAb Das-1 was intense, diffuse, and mostly cytoplasmic (fig 4). Portions of the normal gastric mucosa, including the stroma, did not react with mAb Das-1 (figs 2B, 2C, 3C, 3F, and $4 \mathrm{~B})$.

On reviewing mucin stains $(\mathrm{AB} / \mathrm{PAS}$ and $\mathrm{AB} / \mathrm{HID})$, the majority of the slides showed coexistence of "complete" and "incomplete" GIM phenotypes, with a predominance of either variety, or clearly a "mixed" pattern of staining (table 2). Mapping of selected areas of stained slides showed a consistent correlation between the predominantly "incomplete" type of GIM (type II or III) and mAb Das-1 immunoreactivity (table 2).

Irrespective of group A or group B, 9/10 (90\%) of the "incomplete" type of GIM reacted with mAb Das-1 (table 2).
However, 12/41 (29\%) "complete type" (type I, or small intestinal phenotype) of GIM also reacted with mAb Das-1, suggesting the difficulty in clear separation of incomplete versus complete types of GIM. Nine of these 12 "complete" types that were reactive to mAb Das-1 belonged to group A (GIM associated with cancer) and the remaining three were from group B (GIM without cancer). This difference between groups A and B (9/11 (82\%) v 3/30 (10\%)) was highly significant $(\mathrm{p}<0.0001)$ (table 2$)$. Thus it is clearly evident that $\mathrm{mAb}$ Das-1 reactivity is strongly associated with GIM in the presence of gastric cancer, irrespective of "complete" (type 1) or "incomplete" (types II or III) types, with $82 \%$ and $100 \%$ positivity, respectively (table 2 ). The cancer areas from each of the same patients (paired samples) also reacted with mAb Das-1.

Eighteen of 35 (51\%) GIM samples in group A and 7/41 $(17 \%)$ in group B were of "mixed" variety, as defined by mucin histochemistry. Of these, 18/18 (100\%) samples in group A and 3/7 (43\%) in group B were positive with mAb Das-1, further supporting the assertion of the ability of mAb Das- 1 to identify the "high risk" phenotype in the "mixed" group.

\section{DISCUSSION}

In this study, we have described a monoclonal antibody (mAb Das-1) that showed immunoreactivity in $93 \%$ of specimens of GIM associated with gastric carcinoma (group A) but away from the cancer areas. Furthermore, the gastric carcinoma areas from the same $56 / 60$ patients also strongly reacted with mAb Das-1. Immunoreactivity of mAb Das-1 in this group was similar in both Japanese and NJ patients. However, immunoreactivity was significantly $(\mathrm{p}<0.0001)$ higher in group A compared with GIM in non-cancer (group B) patients, both from Japan and NJ. Using patients from Japan who were at a

Table 2 Comparison of monoclonal antibody mAb Das- 1 and mucin staining (alcian blue/periodic acid-Schiff and alcian blue/high iron diamine) in gastric intestinal metaplasia $(G \mid M)^{*}$

\begin{tabular}{llllc}
\hline \multirow{2}{*}{ GIM } & \multicolumn{3}{c}{ GIM type on the basis of mucin stain } \\
\cline { 3 - 5 } & MAb Das-1 reactivity & Complete & Incomplete & Mixed \\
\hline Group At $(n=35)$ & Positive $(n=33)$ & $9 \neq$ & 6 & 18 \\
& Negative $(n=2)$ & 2 & 0 & 0 \\
\multirow{2}{*}{ Group B $(n=41)$} & Total & 11 & 6 & 18 \\
& Positive $(n=9)$ & $3 \neq$ & 3 & 3 \\
& Negative $(n=32)$ & 27 & 1 & 4 \\
& Total & 30 & 4 & 7 \\
\hline
\end{tabular}

*76/132 samples were available for mucin stainings.

$+\mathrm{GIM}$ areas only, away from the cancer segments.

$\$ 9 / 11(82 \%)$ versus $3 / 30(10 \%)$ : $p<0.0001$. 
higher risk than those from $\mathrm{NJ}$, the data also showed complete lack of reactivity of mAb Das-1 in chronic gastritis in the absence of GIM (group C). These data demonstrate that GIM recognised by mAb Das-1, including both incomplete or colonic-type and complete or small intestinal-type, carries a risk of developing gastric carcinoma.

Gastric adenocarcinoma is the second most common malignancy and cause of cancer related death worldwide. ${ }^{13}$ The prognosis of patients with surgically treated early gastric carcinoma, defined as carcinoma confined to the mucosa or submucosa, is excellent, with reported five year survival rates of $90-95 \% .{ }^{6}{ }^{14}$ This survival rate can only be achieved if gastric carcinoma is detected at an early stage.

Epidemiological long term follow up studies and histological data support the notion that GIM and intestinal-type gastric carcinoma are closely linked. ${ }^{6}{ }^{15} 16$ Colonic-type GIM carries the highest risk for the intestinal-type of gastric carcinoma. ${ }^{67}$ At the present time, GIM (all various types) is recognised by the presence of goblet cells on H\&E, or by $A B$ staining, if goblet cells are not readily apparent by routine histology. The significance of the latter stain has also been a source of some controversy because of its staining of normal neck cells and a "blue blush" in some of the non-goblet epithelial cells. ${ }^{18}$ A combination of mucin stains (AB/PAS and $\mathrm{AB} / \mathrm{HID}$ ) is currently used to differentiate GIM into complete or incomplete varieties, or into types I, II, and III. Subtle changes in the colour shades of these stains-for example, blue, magenta, and purple-are the basis of recognition of these subtypes of GIM. Relying on these colour differences can be labour intensive and largely subjective, with significant interobserver variation. In addition, normal gastric tissue that should show the presence of neutral mucins only may show traces of acid mucins. For example, in the body of the stomach, the base of the glandular pits usually stains a faint blue, and the mucous gland cells a faint gray, suggesting secretion of sialomucin and possibly sulphomucin, respectively. ${ }^{4}$ Electron microscopy and quantification of histochemical staining by image analysis have also been used in the past with variable results. ${ }^{19}$

Immunoperoxidase staining with mAb Das-l can be performed easily using a serial section from a paraffin block, along with routine histology. As mAb Das-l does not react with small intestinal epithelium, ${ }^{8-10}$ its reactivity to GIM demonstrates the presence of a true colonic phenotype of GIM. Furthermore, reactivity with mAb Das-1 results in a crisp golden brown colour restricted to intestinal glandular and goblet cells. These are easy to identify compared with multiple shades of a similar colour in the case of complex mucin histochemistry.

In our experience, a "pure" single type of GIM is less common and, in fact, the majority of our specimens in the carcinoma associated GIM group showed coexistence of both complete and incomplete types of GIM in the same section, with a predominance of one or the other. Eighty two per cent of "complete" type GIM from the gastric cancer group (group A) and only $10 \%$ of the "complete" type from the non-cancer group (group B) reacted with mAb Das- $1(p<0.0001)$. This suggests the difficulty of accurate separation of "complete" type of GIM by mucin histochemistry in relation to the predisposition to gastric carcinogenesis. Furthermore, these data indicate the difference in the cellular phenotype of GIM between the cancer and non-cancer groups, and a strong association of mAb Das-1 reactive epitope in GIM associated with gastric carcinoma.

The significant difference in mAb Das-1 staining between groups A and B was evident, irrespective of the location of tissue, such as in the body or antrum of the stomach. However, it is intriguing that the reactivity of mAb Das-1 against GIM from the overall Japanese patients with no history of gastric carcinoma (group $\left.\mathrm{B}_{1}\right)$ was significantly $(\mathrm{p}<0.01)$ higher compared with the similar group from $\mathrm{NJ}$ (group $\left.\mathrm{B}_{2}\right)(52 \% v 22 \%)$, although mean age in both groups was not significantly different. This difference between the two countries may be due to environmental factors that predispose to the carcinogenic phenotype of GIM in Japanese patients. The difference may also be a result of the chronicity of gastritis and GIM due to $H$ pylori infection which has a higher incidence and early acquisition in Japanese patients compared with those in NJ. This hypothesis is supported by the fact that even within the same population of Japanese patients, mAb Das-1 reactivity was significantly $(\mathrm{p}<0.001)$ higher in $H$ pylori positive compared with $H$ pylori negative patients (68\% v 25\%). The percentage of positivity of GIM to mAb Das- 1 in the $H$ pylori negative group from Japan was in a similar range as that observed in a population from $\mathrm{NJ}^{11}$ and from Boston. ${ }^{20}$ Unfortunately, the $H$ pylori status of NJ patients was unknown but could be expected to be much lower than in the Japanese population. $H$ pylori status was also available for all of the 35 GIM with cancer patients from Japan (group $\mathrm{A}_{1}$ ) but not from NJ (group $A_{2}$ ). Thirty of $35(86 \%)$ patients in group $A_{1}$ were positive for $H$ pylori . Reactivity to $\mathrm{mAb}$ Das-l against this group $\left(A_{1}\right)$ was significantly higher than in the subgroup $B_{1}$ (GIM without carcinoma patients from Japan) (94\% v 52\%; $\mathrm{p}<0.01)$. Similarly, immunoreactivity with mAb Das-1 in GIM from NJ patients, with and without carcinoma $\left(\mathrm{A}_{2} v \mathrm{~B}_{2}\right)$, was significantly different $(92 \% \vee 22 \% ; \mathrm{p}<0.0001)$. These data suggest that chronic $H$ pylori infection clearly predisposes to the colonic phenotype of GIM although there may be additional factors for gastric carcinogenesis. However, irrespective of geographical location and aetiologic factors, colonic metaplasia is strongly associated with gastric carcinoma. Geographic differences in the incidence and distribution of GIM have also been reported, although the phenotype of GIM in these particular patients is unknown. ${ }^{21}$

In a recent study by Glickman et al, the use of mAb Das- 1 was studied in determining the cellular phenotype of Barrett's oesophagus and GIM from various gastric locations in patients without a history of gastric carcinoma. ${ }^{20}$ All cases in their study of a complete-type of GIM from the gastric antrum were negative for $m A b$ Das-1, stressing the fact that there is a lack of incomplete or colonic phenotype in non-cancer patients. Furthermore, in this study from Boston, the frequency of mAb Das- 1 reactivity in GIM from the antrum was comparable with our group B patients from NJ (13\% v 22\%). In our previous reports, ${ }^{10}{ }^{11} \mathrm{mAb}$ Das-1 showed a remarkable sensitivity and specificity in detecting Barrett's oesophagus, and has helped differentiate Barrett's oesophagus from GIM of the gastric cardia. ${ }^{20}$ The $95 \%$ reactivity of mAb Das-1 with specialised columnar epithelium in Barrett's oesophagus by us ${ }^{10}$ and by others, ${ }^{20}$ that has been strongly associated with adenocarcinoma of the oesophagus, ${ }^{22}$ can be compared with the $93 \%$ reactivity in the GIM from gastric carcinoma patients, suggesting a precancerous stage that is detected by $\mathrm{mAb}$ Das-1. This is further supported by the fact that the cancer areas from the same 56/60 (93\%) patients with gastric carcinoma also reacted with the antibody. Indeed, staining in the cancer cells was, in general, more intense and diffuse. These data, in addition to earlier reports, ${ }^{623}$ strongly suggest that a metaplastic process of colonic phenotype is involved in the histogenesis of most of the gastric carcinoma. That mAb Das-1 recognises an epitope associated with precancerous states of epithelial tissue is also supported by its reactivity against chronic cystitis profunda that leads to bladder carcinoma $\mathrm{a}^{24}$ and to adenomatous polyps of the small intestine, particularly associated with familial polyposis and with small intestinal carcinoma. ${ }^{25}$ The smaller percentage (approximately $10 \%$ ) of gastric carcinomas that did not react with mAb Das-1 may have a different cellular phenotype. Indeed, $2 / 4$ nonreactive cancers were histologically of the diffuse-type. In our earlier study, for example, each of the 13 squamous cell carcinomas of the oesophagus did not react with mAb Das- $1,{ }^{10}$ and similarly, carcinoma of the prostate did not react with $\mathrm{mAb}$ Das- $1{ }^{26}$, whereas carcinoma of the bladder did react. ${ }^{24}$ 
In conclusion, staining a parallel paraffin section of GIM with mAb Das-1, in addition to the standard H\&E and $\mathrm{AB} / \mathrm{PAS} / \mathrm{HID}$ stains, can be useful in differentiating the colonic cellular phenotype of IM that is more highly associated with gastric carcinoma. Its reactivity is clearly evident in GIM associated with gastric carcinoma, and is significantly $(\mathrm{p}<0.0001)$ higher than GIM from non-cancer patients, although environmental risk factors such as $H$ pylori status and possibly diet may increase positivity among Japanese and other Asian countries. Some of the mAb Das-1 positive GIM from non-cancer patients (group B) may develop gastric carcinoma after a certain length of time, although this can only be proved by a long term longitudinal study. However, mAb Das-1 may identify the "at risk" group of patients with histological GIM, and thus may help to institute cost effective surveillance.

\section{ACKNOWLEDGEMENTS}

This work was presented in part at the annual meetings of the American Gastroenterological Association 2000 and 2001. KKD is the recipient of the Intel Science Talent Search Award for part of this work. This work was supported in part by research grants NIDDK, ROI DK47673, and ROI DK63618 from the National Institutes of Health, Bethesda MD, USA.

\section{Authors' affiliations}

Z K Mirza, K K Das, J Slate, P S Amenta, L H Griffel, L Ramsundar,

K M Das, Departments of Medicine and Pathology, UMDNJ-Robert

Wood Johnson Medical School, New Brunswick, NJ, USA

R N Mapitigama, Muhlenberg Regional Medical Center, Plainfield, NJ, USA

J Watari, K Yokota, H Tanabe, T Sato, Y Kohgo, Asahikawa Medical College, Asahikawa, Japan

\section{REFERENCES}

1 Baracchini P, Fulcheri E, Lapertosa G. Patterns of intestinal metaplasia in gastric biopsies. A comparison of different histochemical classifications. Histochem J 1991;23:1-9.

2 Matsukura N, Suzuki K, Kawashi T, et al. Distribution of marker enzymes in intestinal metaplasia in human stomach and relation of complete and incomplete types of intestinal metaplasia to minute gastric carcinoma. Natl Cancer Inst 1980;65:231-40.

3 Filipe MI, Ramachandra S. The histochemistry of intestinal mucin; changes in disease. In: Whitehead R, ed. Gastrointestinal and Esophageal Pathology, 2nd edn. New York: Churchill Livingstone, 1995:73-95.

4 Jass JR, Filipe MI. The mucin profiles of normal gastric mucosa, intestinal metaplasia and its variants and gastric carcinoma. Histochem $J$ 1981;13: 931-9.

5 Stemmermann GN. Intestinal metaplasia of the stomach: a status report. Cancer 1994;74:56-64.
6 Blok P, Craanen ME, Offerhaus GJA, et al. Gastric carcinoma: clinical, pathogenic and molecular aspects. Q J Med 1997:90:735-49.

7 Plummer M, Buiatti E, Lopez G, et al. Histological diagnosis of pre-cancerous lesions of the stomach: a reliability study. Int J Epidemiol 1997; 26:716-20.

8 Das KM, Sakamaki S, Vecchi M, et al. The production and characterization of monoclonal antibodies to human colonic antigen associated with ulcerative colitis: cellular localization of the antigen by using the monoclonal antibody. J Immunol 1987;139:77-84.

9 Halstensen TS, Das KM, Brandtzaeg P. Epithelial deposits of immunoglobin G1 and activated complement colocalise with the $\mathrm{Mr} 40$ kD putative autoantigen in ulcerative colitis. Gut 1993;34:650-7.

10 Das KM, Prasad I, Garla S, et al. Specialized Barrett's epithelium shares a colon epithelial epitope as detected by a novel monoclonal antibody. Ann Intern Med 1994:120:753-6.

11 Griffel LH, Amenta PS, Das KM. Use of a monoclonal antibody in diagnosis of Barrett's esophagus. Dig Dis Sci 2000;45:40-8.

12 Beckstead JH. Histochemistry. In: Damjanov I, Linder J, eds. Anderson's Pathology, vol 1, 10th edn. St Louis: Mosby, 1996:176-89.

13 Luk GD. Tumors of the stomach. In: Feldman M, Scharschmidt BF Sleisenger MH, eds. Sleisenger and Fordtran's Gastrointestinal and Liver Disease, vol 1, 6th edn. Philadelphia: WB Saunders Company, 1998:733-57.

14 Bringaze WL, Chappuis CW, Cohn I, et al. Early gastric cancer: 2 year experience. Ann Surg 1986;204:103-7.

15 Lauren P. The two histological main types of gastric carcinoma: diffuse and so-called intestinal-type carcinoma. Acta Pathol Microbiol Scand 1965:64:31-49.

16 Hirota T, Itabashi M, Suzuki K, et al. Clinicopathologic study of minute and small early gastric cancer. Pathol Annu 1980;15:1-19.

17 Craanen ME, Blok P, Dekker W, et al. Prevalence of subtypes of intestinal metaplasia in gastric antral mucosa. Dig Dis Sci 1991; 36:1529-36.

18 Lee RG. Mucins in Barrett's esophagus: A histochemical study. Am J Clin Pathol 1984;81:500-3.

19 Rubio CA, Porwit A, Rodensjo M. Method to quantitate intestinal metaplasia of stomach by image analysis. J Clin Pathol 1988:41:799-801.

20 Glickman JN, Wang H, Das KM, et al. Phenotype of Barrett's esophagus and intestinal metaplasia of the distal esophagus and
gastroesophageal junction. An immunohistochemical study of cytokeratins 7 and 20, Das-1 and 45M. Am J Surg Pathol 2001;25:87-94.

21 El-Zimaity HMT, Gutierrez O, Kim JG, et al. Geographic differences in the distribution of intestinal metaplasia in duodenal ulcer patients. Am J Gastroenterol 2001;96:666-72.

22 Hamilton S, Smith R, Cameron J. Prevalence and characteristics of Barrett's esophagus in patients with adenocarcinoma of the esophagus or esophagogastric junction. Hum Pathol 1988;19:942-8.

23 Correa P. Human gastric carcinogenesis: A multistep and multifactorial process. Cancer Res 1992;52:6735-40.

24 Pantuck AJ, Bancila E, Das KM, et al. Adenocarcinoma of the urachus and bladder express a unique colonic epithelial epitope: an immunohistochemical study J Urol 1997:158:1722-7.

25 Onuma EK, Amenta PS, Jukkola AF, et al. A phenotypic change of small intestinal epithelium to that of colonocytes in small intestinal adenomas and adenocarcinomas. Am J Gastroenterol 2001;96:2480-5.

26 Pantuck AJ, Murphy DP, Amenta PS, et al. The monoclonal antibody mAb Das-1 can differentiate primary adenocarcinoma of the bladder and prostate. B J Urol 1998;82:426-30. 